J. WORKPLACE RIGHTS, Vol. 13(2) 147-166, 2008

\title{
COULD ACTION RESEARCH PROVIDE THE KEY TO TRUE WORKPLACE COLLABORATION?
}

\author{
LINDA TWINAME
}

University of Waikato, Hamilton, New Zealand

\begin{abstract}
Management practices that serve principles of "efficiency" and "effectiveness" in the capitalist understanding of such notions have generated work practices that purport to empower employees under the guise of employee participation programs. In the fieldwork reported here, action research was used as a vehicle to initiate collaborative workplace engagements for the benefit of an organization and its employees. Our results have implications for action researchers and for social construction theory. We found that collaborative behaviors, modeled through action research to all organization levels, have the potential to initiate change toward respectful pluralist engagements. Authentic participation requires a supportive environment in order for organizations and their employees to truly flourish. It became apparent that New Zealand employment law provided a framework within which to work collaboratively, but the will to do so was not fully evident. However, through action research, the participants began to construct their "common sense" (Berger \& Luckmann, 1966: 37) of their shared workplace reality and goals.
\end{abstract}

Too often the way of seeing and living that supports the interests of management as the predominant group is valued and perpetuated through pervasive "common sense." Management's goals are valued above other possible alternatives, even by those who are domesticated or exploited through this (Humphries \& Dyer, 2005). Money, power, and strategically presented symbols and systems are used

(C) 2008, Baywood Publishing Co., Inc.

doi: 10.2190/WR.13.2.d

http://baywood.com 
to encourage workers' compliance with organizational objectives and goals, even at their personal expense. Such hegemonic influence is also associated with processes of assimilation and colonization (Humphries, 1992).

The harnessing of humanity to selective organizational goals, I posit, is counter to the participatory ideals of democratic societies, particularly where people have few other choices of life-sustaining activities, or where they have been misled to believe in the mutuality of benefits. Management practices that claim to support employee empowerment and participation demonstrate that in many circumstances, employees' options and choices are circumscribed in ways that pressure them to intensify the problematic aspects of their employment conditions, even at their own expense. Regardless of the pain caused to individuals, such processes are imposed through overt financial or political power, or through the more subtle effects of hegemonic control infiltrating instrumental values that serve "the system." Barker and Humphries' work shows that such processes are embedded both in organizational processes and in the reasoning employees use to rationalize their compliance (Barker, 1993, 1999; Humphries, 1998).

The intensification of the system and employees' willingness to comply, at the expense of their own and their peers' well-being were graphically illustrated by Barker's (1993) insights into concertive control in self-managed teams. Barker found that group members established workplace norms and values, through which they required members to confirm and perform - to achieve organizational goals. In addition, such tendencies were illustrated in the management classroom simulations described by Humphries and Dyer $(2001,2005)$ who also invited their students to critically reflect upon their domesticating, exploitative, hegemonic assumptions. Workplace pressures, in the form of policies, routines, and peer pressure, as well as the anticipatory socialization intensified in management education, embed the unitarist rhetoric informing almost all collective endeavors (Alvesson \& Deetz, 2000).

In the course of the fieldwork presented here, I worked with the managers and staff of an organization through action research (AR). My goal was to turn hegemonic capitalist power imbalances around, through authentic participative AR processes. AR can be utilized to break the polarization of power imbalance, particularly in environments where power holders become willing to share power. Yet not all forms of AR work toward such ends, and for that reason the philosophical and participative underpinnings of AR are outlined here. The context of change has a vast impact upon outcomes; therefore, the philosophical, legislative, and organizational environments are laid out, as is their influence upon the participants' perspectives. In the fieldwork, the participants and I worked together to develop collaborative ways of engaging, primarily to enhance workplace well-being for those involved. Our research activities generated a range of experiences, responses, and outcomes that are discussed below. 


\title{
ACTION RESEARCH
}

Dickens and Watkins (1999) suggest that action research (AR) is an umbrella term including a range of change management activities within participants' natural environments. Reason (1988) describes it as cooperative inquiry, and Cunningham (2001: 196) highlights its focus on the solution of "real organizational or social problems." Internationally recognized AR experts Reason and Bradbury (2001: 1) define AR as

\begin{abstract}
a participatory, democratic process concerned with developing practical knowing in the pursuit of worthwhile human purposes, grounded in a participatory world view which we believe is emerging at this historical moment. It seeks to bring together action and reflection, theory and practice, in participation with others, in the pursuit of practical solutions to issues of pressing concern to people, and more generally the flourishing of individual persons and their communities.
\end{abstract}

Brydon-Miller, Greenwood, and Maguire (2003: 15-16) propose that action researchers generally recognize that "theory can and should be generated through practice ... focused on achieving positive social change." Practice informs theory, which in turn informs practice. Such processes provide "the insights needed for effective intellectual argument." Through critical theory, action researchers are able "to frame issues of power and identity; to suggest strategies for action and explanations of outcomes which had earlier left us puzzled; to provide structures through which our work could be better understood and our practice improved."

It is difficult to trace a single coherent history of AR. Kurt Lewin is generally seen as its main pioneer in America in the 1940s (Reason \& Bradbury, 2001). Lewin and his collaborator Marrow worked within manufacturing plants owned by Harwood Companies Incorporated, of which Marrow was the chief executive (Marrow, 1969, 1972). The work of Kurt Lewin has become a cornerstone of organizational development and practice, particularly his force field analysis model, which provides insights into change management (McShane \& Travaglione, 2005). Growth in the acceptance of AR has continued in social science research across the world.

Bryceson, Manicom, and Kassam (1982) argue that the AR approach arose out of a critique of positivist assumptions regarding the relationship between the researchers and the researched. Rejecting the possibility or desirability of aspiring to notions of neutrality and objectivity, they contend that AR embraces a wide range of research practices and political ideologies. Recognizing that its principles are general in nature and vary in their degree of political activism, they identify five broad features of AR: (1) a commitment by the researcher to the participants; (2) a close involvement by the researcher with the community of the participants; (3) a problem-centered approach designed to resolve and transform; (4) an educational process for the researcher and the participants, seeking action to solve 
social contradictions; and (5) a set of fundamental principles based upon respect for the participants and their ability to produce and analyze their own knowledge.

Bryceson et al. (1982) acknowledge the practical, idealist nature of AR at the micro level. They consider that the validity of AR is illustrated by participants' capacity to generate and apply solutions to their problems. As they develop their action research skills, participants gain opportunities to expand their perspectives, experience pluralistic practices, and potentially realize the "power of agreement." Generally, action researchers maintain that participants own the knowledge generated, and therefore they work to return this knowledge to the participants.

It is its participative emancipatory foundation that draws me to AR; however, not all AR applications are concerned with emancipation (Brydon-Miller et al., 2003). Research has shown that researchers who conduct AR in organizations often position organizational interests above those of worker "participants." Thus, AR has been used to engender cooperation in practices that participants/ employees might otherwise oppose. Therefore, "empowerment granted or achieved is [or can be] restricted and deceptive" (Cooke, 2006: 667) when participation is not genuinely driven by participants. To facilitate further critique of AR, I recommend Kemmis's (2001) heuristic instruments. Kemmis proposes that there are three distinct approaches to AR, each with a different set of objectives and a different focus upon the value of authentic participation: (1) technical or instrumental; (2) practical; and (3) emancipatory (which, it is argued, is geared to recognize and value individuals, communities, and nations).

[1] a technical or instrumental (or means-ends) interest in the case of empirical-analytic research - that is, an interest in getting things done effectively; [2] a practical interest in the case of interpretive research-that is, an interest in wise and prudent decision-making in practical situations; [3] and an emancipatory interest in the case of critical research - that is, an interest in emancipating people from determination by habit, custom, illusion and coercion which sometimes frame and constrain social and educational practice, and which sometimes produce effects contrary to those expected or desired by participants and other parties interested in or affected by particular social or educational practices. (Kemmis, 2001: 92, emphasis in original)

The technical, instrumental approaches used to achieve outcomes (an improvement in productivity, for example) may well be a manifestation of the "participation" processes exposed by the likes of Barker (1993) and Humphries (1998) as domesticating and exploitative. The application of AR in the service of organizational outcomes, under the guise of participation, may contribute to the intensification of corporate capitalism with its associated challenges. The instrumental ethics that underpin and attempt to justify such exploitation are thus implicitly offensive.

Barker (1993) and Humphries (1998) inspired me to investigate the extent to which a participatory research method could be implemented in a New Zealand 
organization operating under typical market conditions, without generating domesticating outcomes. Intensification of capitalism concerns me as it challenges my deeply held belief in the possibility and necessity for employment practices that are just and safe for all. To guard against cooptation of the work and to invite authentic participation, I engaged the transformational and emancipatory ideals of critical theory applied through an AR project designed to enhance the well-being of employees in the firm.

\section{Employee Participation}

Critical literature exposes the employee participation programs that emerged in the 1980s. The cooptation of participative management practices and discourses of employee empowerment for the intensification of managerial control of employment have been documented by Cooke (2006), Deetz, Grim, and Lyon (2003), Alvesson and Deetz (2000), Barker (1993, 1999), Humphries (1998), and Gastil (1994). I argue that "authentic" participation is a necessary aspect of liberatory processes in political, economic, and all social activity. It is a mandate or implicit assumption associated with the democratic ideals that are promoted along with the freedom (and responsibilities) of/for capital(ists). Toward that end, I set out to work collaboratively with employees to improve their workplace well-being. The research became an opportunity to better understand the effects of a prevailing unitarist ethos and the risks to individuals in challenging that ethos under the emerging reinvigoration of a pluralist perspective (Twiname, Humphries, \& Kearins, 2006) I aimed at the emancipatory aspirations of AR to support participants as they enhanced their shared understandings and developed their skills in working together collaboratively and respectfully.

The "undemocratic" and exploitative processes that are of interest to critical theorists are not always self-evident to organizational thinkers or practitioners. The critique of the emergence of employee "participation" and "empowerment" as processes of intensification of control provides examples of the exposure of exploitation and a call to account for ourselves in terms of the underpinning democratic values upon which all may claim justification for their many rights and opportunities. Given that an uncritical approach to purportedly empowering processes might contribute to the exacerbation of exploitative processes, the value of "doubt" in analytic processes is advocated. However, to embed a condition of mistrust and to limit human endeavors accordingly will not meet the emancipatory aspirations of critical thinkers. Therefore, I explored the extent to which AR might create a "communicative space" (Kemmis, 2001) in which the cooptation associated with hegemonic control might be resisted and through which participants might flourish. Thus, in the fieldwork reported here, I worked collaboratively with participants to contribute to their workplace well-being. I chose a participatory research process that engaged employees in becoming actively involved in the enhancing of their workplace experience. In this choice, I sought 
not only to achieve with them immediate improvements in their working lives but also to contribute to the creation and evaluation of processes built on deconstructive approaches to reconstructive endeavors.

The fieldwork presented here was conducted in New Zealand after a change of government and after new employment legislation became law. New Zealand's Labour-led coalition government initiated what became the Employment Relations Act of 2001 (ERA), in response to social disquiet over the previous government's policies. Fundamentally, the ERA was designed to recognize and redress the inherent power imbalance within employment relationships (Skiffington, 2001). Founded upon the principle of "good faith," it became law through cooperative negotiation modeling the act's own principles. The ERA was designed to promote collaborative, cooperative, and inclusive principles through good faith, mutual trust, and confidence in employment relationships; therefore, it promises greater tolerance of the voicing of plural and conflicting interests than did the previous unitarist legislation (Skiffington, 2001; Wilson, 2001). The ERA sanctions trade union membership (Wilson, 2001) and actively promotes collective bargaining. It recognizes diversity of interests in employment relationships and promotes employee choice, including a choice between collective or individual employment agreements. Its advocates strive to increase New Zealand's productivity through enhanced cooperation, collectivism, and workplace relationships based upon good faith.

Compatible relationships between stakeholder groups are seen as vital for the long term financial, social, and environmental success of organizations. I suggest that the principles upon which the ERA is founded - good faith, cooperation, and collectivism - are entirely consistent with the emancipatory aspirations embedded within AR - enhanced democratic cooperation and participant voice. The ERA provided management with "encouragement" to share a level of power with staff; AR provided a vehicle through which participants (management and staff) could develop emancipatory, participative, and pluralist skills and benefit from their outcomes.

\section{METHOD}

The action research (AR) project was conducted in 2001 and 2002 in a small New Zealand manufacturing facility that was founded in the mid 1970s. In 1996, it was purchased as a going concern by a multinational corporation based in Europe. The shareholders expected a return on capital expenditure within three years. The organizational structure was largely bureaucratic; all recruitment decisions required the approval of the Board of Directors. The New Zealand facility produced large, complex types of machinery to meet specific client requirements. It supplied product to North America, Europe, China, and locally within New Zealand. Management reported that it employed qualified core workers to whom it provided ongoing training and career pathways with a view to 
encouraging ongoing employment. Employment practices were governed, within the law, by the Board of Directors' overall requirement to maximize the return on investment. The local managers continually sought to broaden the firm's client base and aggressively sought means by which to reduce costs. During the period of my fieldwork, the staff numbers included from 33 to 36 skilled core workers. Core workers were paid through salary and significant end of year bonuses. They were highly motivated and skilled, as demonstrated by their tendency to consistently work extended hours without supervision. The firm also employed temporary workers and outsourced the manufacture of components. I was unable to gain access to the temporary employees and outsource component manufacturers; therefore, they were not included in the research.

The fieldwork was not funded by the organization. The local manager committed staff hours to the work over a two-year period. He welcomed my offer to conduct AR in the firm, due to a particular day on which three staff members resigned. Previous to that day he was not aware that staff members were dissatisfied; as a result of the resignations, he realized that communication within the organization needed to improve. He also hoped the project would reduce costs, enhance staff satisfaction, and enable the organization to benefit more fully from staff skills.

Action researchers' participative democratic assumptions require active authentic community involvement in the pursuit of practical solutions that impact upon the participating communities (Reason \& Bradbury, 2001). Action researchers strive to listen to and learn from participants' unique perspectives. Direct and honest communication between those involved is essential. Therefore, when conducting AR in organizations, the staff members are considered to be best equipped to identify and address the problems that may exist in their environment. However, participative processes are generally costly in terms of time- - a factor that is of concern in most financially motivated organizations.

The "echo approach" to action research (developed by Alex Bavelas, a student of Kurt Lewin) provides a semistructured, efficient means through which AR principles can be introduced and modeled to encourage participant interaction, dialogue, and enhanced understanding (Cunningham, 2001). In order to maintain and communicate respect for participants' ability to generate and apply solutions to their own problems (Bryceson et al., 1982), transcripts of their perspectives are kept in their own words. It is argued that when issues are described in the terminology and sentiments of those who originally described them, participants' positions are represented more accurately and are potentially more relevant and perceptive. Researchers do not presume to "correct," edit, or refine the participants' language; thus the views, thoughts, and feelings of participants are echoed (Cunningham, 2001).

Action research methods are not predefined at the beginning of the research; instead they are developed collaboratively between the participants and the researcher(s). In the research presented here, I established an AR process through 
the echo approach, focusing upon the principles of cooperative and collaborative enquiry. In particular, I aimed at the emancipatory aspirations of AR (Kemmis, 2001). Dialogue was central to the processes (Habermas, 1971) as the participants and I worked to discover their various perspectives. The echo approach provided an entry point that proved acceptable to organizational efficiency requirements, while introducing AR spirals of participant lead planning, action, and evaluation of projects that participants had identified, planned, and implemented.

Our approach was to establish a steering committee of volunteers from all levels of the organization, to work collaboratively on behalf of and with their fellows. In our quest to find new solutions to old problems, openness to new ways of looking at things was encouraged. Under my guidance, the steering committee invited participant engagement in action research programs. We used echo approach processes to identify staff organizational and interpersonal needs, concerns, and wishes. Open questions were used to avoid directing participants' responses (see Appendix 1). Such questions are termed "echo questions" as they are designed to identify individuals' values and beliefs through an open, confidential method of questioning.

The steering committee and I conducted focus group interviews yearly with all available core staff members. Their responses were categorized and sorted by steering group members and myself. The sorting process required intuitive consideration of participants' responses, so that a collective view of the issues or problems could be achieved. In consultation with the steering committee, I wrote reports for the managers and staff from the categorized transcripts of our focus group interviews. In doing so, I strove to maintain the participants' voice and to serve them in their efforts to address their concerns and aspirations.

Our reports offered feedback to management, the steering committee, and the staff in general. They also communicated staff perspectives, enhanced the plurality of perspectives, and enhanced communication. In part, the reports served as interventions; they also identified areas where additional actions were required. The steering committee prioritized staff concerns and invited staff to work with them to identify and implement solutions through ongoing processes of participative enquiry. They also used AR enquiry to measure the degree to which they had addressed the identified needs.

The redesign of the computerized timesheet record system provides an example of staff members working through AR to introduce solutions to an area of concern to staff. This was a major project involving staff and an information technology (IT) expert. Previously, staff members had been frustrated with the system, as it limited the detail that they were able to record, resulting in criticism from supervisors. Once the system was redesigned, staff members were able to justify the use of their time more fully (they regularly improve the design of machines without being directed to do so); and the organization was able to tender for new work more accurately, as time usage for redesign and production was 
more clearly identifiable and subsequent projects were built according to the improvements the staff had made.

To enable multiple points of entry into our projects, to build in authenticity, and to expose potential cooption of their work, I invited staff from within the firm to join and/or critique our projects at any time. Through this method, I also worked to initiate dynamic cooperative enquiry. Overall, the research entailed the design of an umbrella program of AR that involved the identification, establishment, guidance, and evaluation of several smaller projects with all levels of core staff. A number of participative changes were initiated (see Appendix 2), as the research projects focused on participant-led attempts to achieve specific workplace changes that were identified by staff. AR provided a vehicle through which participants enhanced their shared understandings and practiced collaborative, respectful ways of working together. The success of our authentic participation through AR became evident: through staff spontaneously initiating new projects in which management and I were not involved; through the choices that staff made to volunteer to become involved in our AR projects; through the enhanced trust engendered between staff members; and through the changes that management became willing to make. An overview of the above mentioned results is provided below.

\section{RESULTS}

First, however, I provide excerpts from conversations with participants gathered during our participative enquiry. The excerpts show historical, underlying worker tensions. My work to pursue more pluralist democratic processes toward democratic communication did achieve some level of enactment (Twiname \& Humphries, 2006). From management through to the shop floor, staff members reported that they were invigorated by the project and developed a commitment to more nurturing and inclusive practices. This claim is supported by the firm's financial controller, who made the following statement regarding the AR project and the firm's adoption of more inclusive management practices:

It has been great. I have actually really enjoyed it. My general interest tends to be more in management issues anyway. I do not enjoy accounting that much. It has been a way for them [the multinational organizational managers] to keep me within the group. I think they are pretty comfortable with the way it has gone. . . I have gone a full circle. I started my career as a truck driver for three years, then I went back to university, back into finance and became an accountant. It was all bottom line. When I first came back into the accounting world it was all that I was concerned with. In the last year I have looked back and thought, would I have liked to be treated as a general staff member, when I was driving trucks, as we treat our staff now? In some areas I think it is not very good at all, in hindsight. . . Maybe I have shifted a little from the capitalist pig that I was. 
The following excerpts show the depth of participant insight. For example, as a result of our AR, the financial controller was willing to move toward more pluralist ways of engaging with staff. But his willingness was constrained by the parent company and its shareholders:

I [the financial controller] think that one thing the staff do not realise is the significant amount of pressure that is brought to bear from outside. From the market: they have no ideas of what it is like to work within the boundaries of the practices that we have to work within. The German parent company is very capitalist oriented to companies and very harsh to companies if it is not perceived in the right light. Shareholders in German companies, in my mind anyway, seem to be extremely unforgiving about negative results in accounts. So if you do not meet your targets, your share price seems to drop. You really have to do what you say to your shareholders you are going to do. That is just my impression, having seen what has happened over the years with our company. . . .

Maybe they have been quite smart, that in Germany they work to make themselves look good and they push the harsh practices out to the other companies around the world. Maybe I am being a bit cynical. I suspect there will be very good high staff levels in most companies in Germany, because they are very nice, socially responsible people in that country. But in New Zealand, no, you cannot have staff, make them work harder.

Management implemented ERA requirements through a discourse more consistent with a unitarist position than with the pluralist principles upon which the act was founded. Despite new legal requirements, union membership was overtly discouraged. In response to my questions as to why a particular employee had not sought union support, the employee replied: That would be a card I could play only once. He reported that management would find covert ways to punish staff members for attempting to gain support from a union. He suggested that staff members who subscribed to union membership would be assigned less desirable work and/or that their employment might be terminated for "other" reasons.

Management appeared to maintain tight control through fear. This was made clear in the focus group interviews with staff members in the second year of research. Staff members expressed their concerns regarding job security and management's use of employees' fear to maintain control. The following comments illustrate employees' views at that time, shortly after the employment of three core workers was abruptly and unexpectedly terminated:

- What do the guys think about job security here?

- It [the possibility of redundancies] rears its ugly head again.

- You never know.

- The company has a name for it now.

- The way it was done, I feel, was not appropriate.

-We get a bit scared. Are they going to get rid of some other people off the floor? 
- The answer to the big question of "is that the end of it?" Management said, well, you never know what is around the corner.

- Job security is almost more important than money.

- Is it the person or the job [that is] redundant? Can people be repositioned?

Staff members clearly wanted management to explain and even justify its decisions, particularly with regard to termination of employment. The ERA requires parties to engage in good faith; however, it seemed that management was not willing or not experienced in working pluralistically in consultation with the staff. The following comments illustrate staff members' deep suspicion of management:

- With regard to the redundancies, a lot of speculation is going on. Personal issues do not need to be discussed, but the outline should be provided to staff [by management].

- I do not think that anybody really believes the company line that the jobs have been realigned.

- [A specific supervisor] is going back to greener pastures. Not true!!! He is going back to the same company for the third time. Why was he made redundant?

Staff members were concerned about the performance review process used by the firm. They wanted to be involved in its design and were skeptical about management's commitment to it. The following unsolicited comments reflect their concerns:

- Interviews for the performance reviews need to be held on a regular basis. It would be good to have more than two people at the interviews, our immediate supervisor and somebody neutral.

- We need more information of how to prepare for the performance reviews and how the information is used.

- They are supposed to be quarter yearly and we missed the last one.

- Twice a year could be quite good.

- If they make a rule they should make it happen.

- If something is identified out of the performance review, this should be actioned within a short time frame. For example, courses that people would benefit from.

- Why do a performance review if you do not go through with the recommendations made?

During our AR projects and meetings with individuals, I encouraged participants to critically reflect upon their interpersonal engagements. Overall, I sought ways to focus pragmatically on mutually agreed emancipatory objectives. For example, initially the financial controller did not appear to value collaborative enquiry with staff. Often he told me he could make decisions much faster without 
consultation. But over time, he came to value the perspectives of staff and to recognize the value of consultation and of explaining management decisions to the staff:

They have to get over some things; it is part of growing up, as far as I am concerned, that you are not always going to have your own way. You need to be mature enough to say, well, OK, we have suggested something but management have said no for a particular reason. But it is management's responsibility to let you know that reason. Too often I think in the past we have just said, "NO, you cannot." That is why I wrote about the communication issues in my report. To me it [the concerns raised by staff members in our second set of focus group sessions] is a very strong indicator that communication lines need to be better throughout the company. Very simply by talking to somebody about it, some of these problems would have gone away. Why fester for a year when you could have gone and spent two minutes talking?

The financial controller grew to value AR's potential. In addition, he demonstrated renewed respect for others' perspectives. However, pluralist commitments were not realized at all levels of the organization. Some projects disproportionately benefited the organization to the subtle detriment of the employees. The manager and the human resources (HR) manager did not appear to value consultation with employees; collaborative, consultative work alongside employees appeared to be foreign to them.

One year into the research, staff members told me that initially they were suspicious of the project - as management supported the work and staff had little trust in management, staff members were suspicions. Once the confidential and respectful nature of the work was proved and we had achieved outcomes that staff members valued, many became fully committed to the work. In the second year, they initiated AR projects independently of me. To varying degrees, management and staff were aware that the new employment legislation afforded greater protection to workers. It became apparent that neither party was equipped for a move toward collaborative ways of engaging within a workplace environment as promoted by the ERA.

AR facilitated a shift toward working collaboratively to improve workplace practices, enhance employee well-being, and develop healthy ways for staff at all levels to work together. Through AR, the staff collaboratively developed practical skills and insights. They identified, designed, and initiated a range of specific change projects through ongoing processes of research, action, reflection, and theory development and application (Reason \& Bradbury, 2001).

\section{DISCUSSION}

I view the harnessing of humanity to selective organizational goals as counter to the participatory ideals of democratic societies. Any associated exploitation is a 
violation of justice. Management practices that serve the principles of "efficiency" and "effectiveness" in the capitalist understanding of such notions have generated work practices that purport to empower employees through employee participation programs. Under such conditions, the paradigm by which employee "participation" is framed has circumscribed employees' "options" (Barker, 1993, 1999; Humphries, 1998). Domesticating and colonizing effects are exacerbated by adherence to a unitarist ideology and the instrumental logic that serves owner interests dressed in the garb of organizational growth, efficiency, productivity, or survival.

Berger and Luckmann (1966: 20) propose that different groups have different understandings (social constructions) of their reality. Our perceptions of what we (think that we) know is influenced (given meaning) by those around us. "The specific shape into which this humanness is molded is determined by those socio-cultural formations and is relative to their numerous variations" (Berger \& Luckmann, 1966: 67). Overall, Berger and Luckmann suggest that our realities are constructed to greater or lesser degrees, whether constructed by ourselves or imposed upon us by others. In the research presented here, I worked to encourage the participants to construct their own realities in their workplace for the benefit of the organization and its employees.

I sought to model authentic participant-led enquiry so that the participants might experience and assess the value of pluralist, cooperative principles. Toward that end, I chose a participatory research process through which employees became actively involved in the enhancement of their workplace well-being. My philosophical goal was to demonstrate that knowledge is socially constructed, so that through this understanding, participants might realize a plurality of perspectives and enhance their capacity to inscribe new meaning and new outcomes into their lives. I hoped that they would extend their understanding of a "common sense" (Berger \& Luckmann, 1966: 37) of their shared workplace reality and goals. In opening and supporting the possibility of change, I worked toward practical outcomes for the benefit of the organization and its employees. I was guided by the participants; once relationships were established, participants set directions. I consider that the value held for participative AR is evident in their ownership of the project.

The research provided authenticity through first-, second-, and third-person reflection. White (2004: 130) suggests that first-person research "can be understood as a process of explicitly developing inquiry practices to examine personal experience." Participant perspectives were generated and gathered through focus group interviews. Under the guidance of steering group members and myself, the participants led the focus group discussions using echo questions to generate insights into staff perspectives (see Appendix 1). I acted as their scribe, recording their conversations without recording names (to provide a level of confidentiality). Occasionally I asked questions to clarify or to probe for their insights. Through this process we moved into second-person research, where we 
created "a community of learning through interpersonal dialogue and other forms of conversation with others" (White, 2004: 130). In part, this was achieved through the reports I wrote for management and all participants (under the supervision and guidance of the steering committee, which assisted in the analysis/grouping of responses). Later, the steering committee and I prioritized projects and invited staff involvement. The reports also enabled third-person research, which "can be understood as participation in a larger community where personal interaction may not be possible, and includes writing and other processes for documenting inquiry" (White, 2004: 130). I offer my third-person evaluations here through an analysis of the project and AR's potential to facilitate liberatory outcomes in workplace settings.

Through participative AR communicative processes, we altered the social construction of reality in the workplace in several ways. The employee participants built upon their mutual trust by self-initiating collaborative work to generate improvements in workplace practice and their own well-being; they developed the capacity for staff from all organizational levels to work respectfully together, including the capacity to complain to management; they constantly critiqued the work for unexpected outcomes and cooption; and they developed the skills needed for authentic workplace collaboration and a commitment to such collaboration. The program inspired some management and staff members to move toward more pluralist, emancipatory ways of engaging. Unfortunately, we did not turn the organization into a workers' paradise, but we did shine light upon the benefitsfinancial, personal. and developmental — of workplace collaboration.

The employees benefited from participative AR practices in their workplace in a range of ways. They initiated and implemented improvements. AR provided a means through which they were able to voice their views more fully than was otherwise possible - in a nonunion organization - without negative employment consequences. Staff were able to express to management their concerns regarding pressure of work; as a result, shareholder approval was gained to employ additional staff. Staff members from all levels realized the importance of working collaboratively and respectfully. They listened to and empathized with each other, which enabled them to work more efficiently and also enhanced their well-being in their work life. For example, the financial controller realised that he had a responsibility to explain and justify management decisions more fully to general staff members. As a result, as Koster and Sanders (2006) suggest, organizational citizenship was enhanced. Participants from all levels of the organization reported that they were invigorated by the project and developed a commitment to more nurturing and inclusive interpersonal engagement.

The firm benefited through enhanced employee engagement and participation, using skills that had previously remained latent. AR engagements developed valuable employee skills and enhanced organizational commitment-potentially addressing the manager's retention concerns. Appendix 2 outlines a range of projects that staff members implemented through AR. They also spontaneously 
initiated other projects through AR engagements. Overall, the AR projects benefited both the organization and its workers.

The research was conducted during a transition into employment law founded upon collaboration. The effects of this new law were merely beginning. Participants reported and demonstrated fear resulting from management practices under the Employment Contracts Act of 1991 (ECA), employment legislation founded upon litigious, unitarist, neoliberal assumptions, while being employed under the Employment Relations Act of 2000 (ERA), employment legislation designed to engender goodwill and trust. I found that the ERA's claimed pluralist tolerance had limited influence. Legislative attempts to enhance the emancipation of citizens through an invigorated pluralist approach to human well-being were not sufficient in a social context in which employees and their unions have long been domesticated. Not all of those involved embraced a collaborative intent, as was illustrated by the manager's actions and comments. He did not embrace the philosophy upon which the ERA was based, but he focused instead upon minimal legislative requirements. The company's interests continued to dominate significant decisions. Participants in the research demonstrated willingness to express their hopes and aspirations, but when those interests were deemed inappropriate by management, a subtle but nevertheless profound response of disgruntled compliance was the result. This outcome indicates that while the hegemonic conditions of a unitarist ethos had not been fully achieved in the workplace, the benefits of respectful relationships sought under a pluralist legislative framework were also missing.

I suggest that we can never be entirely sure that hegemony is not present in "participative" research; undemocratic and exploitative processes are not always self-evident. I worked to minimize exploitation by encouraging participant critique and by valuing multiple perspectives. As a result, staff members made more decisions for the benefit of the organization and themselves; they also became more open in their critique of management practices. Management conceded some of its control; for example, the financial controller changed his outlook from that of "the capitalist pig" that he once had been. However, a top-down/parent-child relationship remained. It takes time, will, and skill to develop and grow into new realities.

\section{CONCLUSIONS}

The fieldwork provided a practical change instrument through which pluralist practices were modeled and many were valued. The law provided a context that supported this change; however, through the work it became apparent that staff and management lacked participative skills. Initially, the workers moved with caution due to their feelings of vulnerability and inexperience in participative workplace practice. Over time they gained confidence, but unfortunately the manager appeared to be threatened by a perceived loss of control. I recommend 
that researchers considering undertaking participative AR in workplace settings first ensure that power holders in the organization are open to the frank upward communication that it can initiate and that they are willing to share some level of power.

Until humanity has reached the ability or willingness to behave in mutually life-enhancing ways, I suggest that legal regulation to constrain exploitation is a necessary condition for a safe and fair society for all. British-based laws and polities based on them (such as New Zealand's), are generally cast in terms of oppositional and instrumental discourses. They are "won" by the combative style of parliament and their meaning and application are "fought over" in courts of law. It is unlikely that this discourse could evolve into something more collaborative without transformative attention to its modality. However, while it is the mode of framing workplace relationships in this country - and increasingly the model followed by the global economy-it remains as a framework upon which more ethically driven discourses are constructed. There is now a general revival of legal and policy interest in conditions of employment, worker wellbeing, and work-life balance projects. There is also a greater recognition of the contribution that unions and other advocacy groups make to the balancing of power in societies committed to capitalist forms of economic endeavor.

Hughes (2004) found that initially the New Zealand National Party, the Employers' and Manufacturers' Association, and the New Zealand Business Roundtable - organizations that advocate unitarist assumptions - expressed their concerns regarding the ERA in its early stages of development and implementation. But in 2004, Hughes reported, they were largely comfortable with its application. It seems that the employer organizations that Hughes reported upon had realized that the changes the new employment law was designed to foster were difficult to implement and measure. The research reported here supports this suggestion. Unitarist assumptions and ways of engaging were deeply embedded in management practices, and management did not demonstrate the skill or the desire to change. Inclusive, collaborative ways of engaging were foreign. In order to engender pluralist insights and skills, I argue that management academics, employer representatives, and employee representatives need to expand accepted wisdom to enable the managers of tomorrow to take a more critical, inclusive view of their responsibilities and management practices and to realize the mutual benefits they can achieve.

The fieldwork reported here facilitated a deeper understanding of the impact of neoliberal ideals and power dynamics within organizations beyond the site of study. Despite employment legislation designed to provide environments in which goodwill is valued (Skiffington, 2001), respectful pluralist relations were only sometimes evident. Participative work practices implemented through ARacting in good faith and in partnership - provided the means through which both organizational and worker needs could be met. The research revealed participants' willingness to work toward organizational and personal goals. However, they 
were able to achieve only limited resistance to a unitarist ethos through AR. It became apparent that the research participants' previous experiences inhibited their capacity to resist exploitation, and at that time the manager was not willing to soften his hold on power. The collective (un)conscious appeared to outweigh the emancipatory effect sought through more democratic legislation. The ERA did not provide the level of protection its authors sought to achieve. More was required to enhance worker rights and democracy. Emancipatory AR was not fully effective in engendering pluralist engagements, while working toward practical outcomes for the benefit of the organization and its employees. Yet the fieldwork demonstrated that $\mathrm{AR}$ has the potential to initiate change toward respectful pluralist engagements if these engagements are fully supported at the highest management level. More work is required to model pluralist ways of engaging in order to overcome the prevailing neoliberal, unitarist ethos. I encourage action researchers to share their results with the academic community so that we can develop the body of knowledge about AR in the workplace and reconstruct social realities for the betterment of workers (and their employers).

This article makes a contribution to practice in the workplace and to emancipatory ways of working together beyond the field of study. Fostering the power of agreement involves turning away from investment in practices of instrumental control. Over time, ethical practices can facilitate change away from cooptation and colonization to open opportunities for frank communication toward mutually agreed goals. The potential benefits of such practices are threefold. First, enhanced personal satisfaction, integrity, and well-being are available for those who engage in more healthy, open dialogue and who agree upon their actions. Second, enhanced organizational practices can be achieved through robust co-enquiry and participation. Third, personal and organizational costs can be reduced, due to healthier, happier employees, including a reduction in the costs associated with stress, health, and staff retention issues. Financial savings were not the primary focus of this project; nevertheless, the financial controller acknowledged that such savings did result from employees' fuller involvement.

\section{APPENDIX 1 Echo Questions for Understanding Staff Interests}

Consider the various interests you have in the firm. We would like to ask some questions about them.

1. (a) What do you find satisfying about your working relationships with people in this organization?

(b) What do you find less satisfying about the working relationships with people in this organization? 
2. (a) What are some positive things you would like to happen in improving the working relationships?

(b) What are some less positive things you see happening in the working relationships?

3. (a) Could you give some examples of things that individuals or groups do that are helpful to you in your job?

(b) Could you give some specific examples of things that these individuals or groups do that are not so helpful to you in your job?

4. (a) What ideas do you have for improving things in the organization?

(b) What projects do you have for improving things in the organization?

5. (a) What do you think we can do to make us [the staff] more effective?

(b) What would/could hinder our effectiveness?

6. (a) What are some things which you think management(s) could do to help you in your work?

(b) What are things which we [the staff] should/could do to help management?

7. (a) What projects could we as the Steering Committee take on in response to some of these ideas?

(b) What projects should we as the Steering Committee not take in response to some of these ideas?

\section{APPENDIX 2 The Main Projects}

- The steering committee identified and engaged in a series of actions in response to the interviews, in consultation with staff and management;

- Flowers were presented at a staff meeting in appreciation for a staff member's ongoing efforts and presented to another to celebrate the completion of a degree;

- Nonalcoholic drinks were made available at staff functions as suggested in the interviews;

- A major project was undertaken to redesign the computerized timesheet record system. This project was conducted by a team of staff members from the firm, under the direction of steering committee members. Action research principles were embraced through involving staff in design and pilot tests;

- A series of staff presentations was introduced during meetings, in order to enhance communication and understanding between departments, in addition to encouraging staff input. The steering committee also suggested that management provide more information before meetings so that staff members might be able to prepare themselves to speak if they wished;

- A "one stop shop" area for detailed information on each project was established and maintained. It reduced staff aggravation, reduced misunderstandings, and improved efficiencies in the firm; 
- A debriefing process was initiated for the completion of projects, designed to improve communication and efficiencies in future work. Project debriefing was included in the documented sign-off process to ensure that the debriefing process would take place;

- A special project was initiated by a steering committee member to look into methods for recognizing staff efforts in addition to salary;

- Signs were mounted onto machines on the shop floor to assist in their identification;

- A library was established to house and track key update documents;

- Management's quality assurance project included general staff involvement through action research methods;

- Staff members explored the possibilities of a new uniform and invited sponsorship by suppliers; and

- Decision making was increasingly implemented through participative enquiry.

\section{REFERENCES}

Alvesson, M., \& Deetz, S. 2000. Doing critical management research. London: Sage.

Barker, J. 1993. Tightening the iron cage: Concertive control in self-managing teams. Administrative Science Quarterly, 38: 408-437.

Barker, J. R. 1999. The discipline of teamwork: Participation and concertive control. London: Sage.

Berger, P. L., \& Luckmann, T. 1966. The social construction of reality: A treatise in the sociology of knowledge. London: Penguin Press.

Bryceson, D., Manicom, L., \& Kassam Y. 1982. The methodology of participatory research approach. In Y. Kassam \& K. Mustafa (Eds.), Participatory research: An emerging alternative methodology in social science research: 67-82. New Delhi: Society of Participatory Research in Asia.

Brydon-Miller, M., Greenwood, D., \& Maguire, P. 2003. Why action research? Action Research, 1(1): 9-28.

Cooke, B. 2006. The Cold War origin of action research as managerialist cooptation. Human Relations, 59: 665-693.

Cunningham, J. 2001. Researching organizational values and beliefs: The echo approach. Westport, CT: Praeger.

Deetz, S., Grim, A., \& Lyon, A. 2003. Communicative praxis and collective decision making: From phenomenology to the politics of experience to dialogic constitutive practices. In E. Ramsey \& D. J. Miller (Eds.), Experiences between philosophy and communication: Engaging the philosophical contributions of Calvin O. Schrag: 55-71. Albany, NY: State University of New York Press.

Dickens, L., \& Watkins, K. 1999. Action research: Rethinking Lewin. Management Learning, 30(2): 127-140.

Gastil, J. 1994. A definition and illustration of democratic leadership. Human Relations, 47: 953-975.

Habermas, J. 1971. Knowledge and human interests. Boston: Beacon Press.

Hughes, J. 2004. The sky is falling . . . again. Employment Law Bulletin, 7 (October): 77-93. 
Humphries, M. 1992. Working with our differences: A contribution from New Zealand. Journal of Management Education, 14 (Supp.): 28-42.

Humphries, M. 1998. For the common good? New Zealanders comply with quality standards. Organizational Science, 9: 738-749.

Humphries, M., \& Dyer, S. 2001. Changing the nature and conditions of employment: Stimulating critical reflection. Journal of Management Education, 25: 325-340.

Humphries, M., \& Dyer, S. 2005. Introducing critical theory in the management classroom: An exercise building on Jermier's "Life of Mike." Journal of Management Education, 29: 169-195.

Kemmis, S. 2001. Exploring the relevance of critical theory for action research: Emancipatory action research in the footsteps of Jurgen Habermas. In P. Reason \& H. Bradbury (Eds.), Handbook of action research: Participative inquiry and practice: 91-102. London: Sage.

Koster, F., \& Sanders, K. 2006. Organisation citizens or reciprocal relationships? An empirical comparison. Personnel Review, 35: 519-537.

Marrow, A. J. 1969. The practical theorist: The life and work of Kurt Lewin. New York: Basic Books.

Marrow, A. J. (Ed.). 1972. The failure of success. New York: Amacom.

McShane, S., \& Travaglione, T. 2005. Organisation behaviour on the Pacific Rim. New York: McGraw-Hill.

Reason, P. 1988. Human inquiry in action: Developments in new paradigm research, London: Sage.

Reason, P., \& Bradbury, H. 2001. Introduction: Inquiry and participation in search of a world worthy of human aspiration. In P. Reason \& H. Bradbury (Eds.), Handbook of action research: Participative inquiry and practice: 1 -14. London: Sage.

Skiffington, L. 2001. The making of the ER Act-A recipe for success. Employment Law Bulletin, 3 (April): 37-64.

Twiname, L., \& Humphries, M. 2006. Out of the iron cage: Employee liberation through communicative action. International Journal of Knowledge, Culture and Change Management, 4: 1740-1754.

Twiname, L., Humphries, M., \& Kearins, K. 2006. Flexibility on whose terms? Journal of Organizational Change Management, 19: 335-355.

White, A. M. 2004. Lewin's action research model as a tool for theory building: A case study from South Africa. Action Research, 2(2): 127-144.

Wilson, M. 2001. New Zealand's path forward. Employment Law Bulletin, 1 (January): $1-16$.

Direct reprint requests to:

Linda Twiname

Waikato Management School

University of Waikato

P.O. Box 3015

Hamilton, New Zealand

e-mail: Lindat@waikato.ac.nz 